v. 13, n. 1

Vitória-ES, Jan.-Feb. 2016

p. $24-46 \quad$ ISSN 1808-2386 DOI: http://dx.doi.org/10.15728/bbr.2016.13.1.2

\title{
Coproduction Factors in Strategic Networks
}

\author{
Cristiano de Oliveira Maciel ${ }^{\dagger}$ \\ Pontifical Catholic University of Paraná \\ Camila Camargo ${ }^{\Omega}$ \\ Paraná Federal University
}

\begin{abstract}
This study addresses the concept of coproduction factors of primary (hub) and secondary (partners) agents in strategic networks of shared service provisioning. Coproduction factors in networks refer to resources of primary and secondary agents. These resources are mainly employed in shared service provisioning and perceived as fundamental by the user. The objective of this research was to verify the influence of these coproduction factors alone and in interaction (network effect) about the attitudinal consequences of user satisfaction and pride of the distance education service. The survey with 7138 users of this service, the validation of measures and the hypotheses test, through the Multiple Regression Analysis, showed that the coproduction factors of the different agents (hub and on-site education poles), as well as the network effect, influence the student's satisfaction and pride.
\end{abstract}

Keywords: Strategic networks. Coproduction factors. Attitudinal outcomes.

* Author for Correspondence:

$\dagger$. Doutor em Administração pela Pontifícia Universidade Católica do Paraná.

Vínculo: Professor do Programa de Mestrado e Doutorado em Administração da Pontifícia Universidade Católica do Paraná. Endereço: Rua Espírito Santo, no. 411, Curitiba - PR - Brazil CEP: 80630-200.

E-mail: cristiano.maciel@pucpr.br

Telefone: (41) 3029-1696

\footnotetext{
${ }^{\Omega}$ Doutora em Administração pela Pontifícia Universidade Católica do Paraná

Vínculo: Professora do curso de Administração da Universidade Federal do Paraná

Endereço: Rua Espírito Santo, no. 411, Curitiba - PR - Brazil CEP: 80630-200.

E-mail: caca.adm@gmail.com

Telefone: (41) 3029-1696
}

Note from the Editor: The article was accepted by Emerson Mainardes. 



\section{INTRODUCTION}

rganizational networks, especially those based on alliances (LUO, 2008),

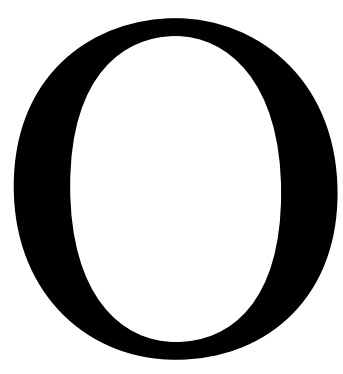
have been investigated from its dynamic formation, governance mechanisms, evolution, global performance and consequences for the constituent agents of such arrangement (KOKA; MADHAVAN; PRESCOTT, 2006; GULATI, 1998; GULATI; LAVIE; SINGH，2009; LUNNAN, 2008). Among these research areas, one of the most explored research lines has been directed to examine the network effect on its primary agents (central organization or hub) and secondary agents (partner organizations in the alliance). However, such studies are usually restricted to the economic results of what is called "network effect".

Under this approach, we find studies in which we verify the occurrence of variations on organizations' share prices after announcing particular alliances (GULATI, 1998), lower organizational performance after entry into networks (GOERZEN, 2007) and several other studies on the relationship between the networks' structural characteristics (e.g. structural embeddedness). Other studies have investigated the contents of interorganizational relationships (relational embeddedness) and its effects on assets returns (SHANER; MAZNEVSKI, 2011; YU; GILBERT; OVIATT, 2011; SAMPSON, 2007; KOKA; PRESCOTT, 2008; OZCAN; EISENHARDT, 2009; LU; MA, 2008).

From these findings, this study highlights the need to go beyond an examination of the network effect on economic measures of the organizations in alliances. The consequences for the organizations involved in this type of arrangement are objective, but also subjective. Reputation (AREND, 2009), status, legitimacy, satisfaction, loyalty and perception of service quality of the primary agents (hubs) and secondary agents of the network are also worth mentioning, above all as it is recognized that such subjective indicators impact objective indicators (e.g., economic performance). Generally speaking, contemplating reviews (subjective), that any stakeholder does on any organization in network, it opens up new opportunities for the advancement in theorizing about the network effect.

Therefore, it is stated in this paper that the network effect is manifested, not only on economic results, but also on relational outcomes of attitudinal nature, especially in the case of alliances for shared services provision. In such types of networks the primary agent is responsible for providing a part which is considered the platform of the experience of the user's consumption experience, the secondary agent responsible to give support or to 
compliment some of the needed activities that the primary agent delegated for reasons of cost, convenience or lack of resources. Therefore, secondary agents are intermediary organizations (ZHANG; LI, 2010) who may influence the assessment that the user does of the primary agent. It is worth mentioning that services provided by secondary agents influence the assessment of services provided by primary agents and vice versa. Thus, the choice in examining the influence of a type of agent over another is above all methodological.

In so far as aiming to examine the relational consequent of attitudinal nature to test the network effect in the context of services, two constructs are identified in the literature as important, though not yet explored: the satisfaction and pride of the service user provided over networks. The choice of user satisfaction variable is justified by this construct being composed by both a cognitive as by an affective dimension, and also because it is related to loyalty and often associated with the economic results of organizations (ANDERSON; FORNELL; LEHMANN, 1994; FORNELL, 1992).

The choice of the user pride variable is due to the fact that this construct also has affective formation but it is a self-conscious emotion (OLIVER, 2010), which represents a positive evaluation on reaching a goal, as the decision of the service user to relate to a particular organization. While satisfaction stems from external attributes to the individual, pride has an internal locus of attribution, which means that this emotion depends more directly from consumers themselves, and marginally from product characteristics. In addition, this variable is shown to be even more important as it has an effect on the reputation of the network agents acting as service providers.

In order to verify how the network effect is related to its consequent attitudinal we develop here the concept of co-production factors. Coproduction factors in networks refer to resources of primary and secondary agents. These resources are centrally employed in shared service provisioning and perceived as essential by the user. According to this consideration, the agents present in the network contribute differently in providing the service through the network structure, because of the differentiation in the resources of the primary agent (hub) and resources of the secondary agents (hub partners). Due to the complementarity of production factors, an agent can influence the performance of production factors of another agent, and thus produce indirect effects (moderation) on relational consequent of economic and attitudinal nature.

It is worth noting that the role of network resources in interorganizational relationships has been analyzed by Gulati (1999) who through field studies and panel data analysis 
confirmed the influence of potential partners' resources in the decision formation of new alliances. Lin, Yang and Arya (2009) also emphasized partners' resources in alliances, and point out that the complementarity between the assets of different organizations is related to performance, which was assessed by the measurement of return on assets. Kang, Mahoney and Tan (2009) found that investments in specific network partners produce spillovers (consequences) of reputation and knowledge for primary agents with this form of arrangement. Gulati, Lavie and Singh (2009) verified that the experiences with partners from some relationships influence the creation of value in the network, but that this influence is moderated by the difference of the resources of younger or older partners.

In line with these studies, and also due to the necessity of examining the influence of the coproduction factors and of the network effect on attitudinal relation consequents, we defined the following research objective: to verify the relation between the performance of coproduction factors of a primary agent (hub or distance education center) and various secondary agents (440 learning centers scattered throughout Brazil) and of the network effect (interaction between these agents' factors performance) on satisfaction and pride of users (students), with a distance learning higher institution (hub) in Brazil.

From this objective derive the following theoretical contributions on shared services delivery networks: (i) the development and testing of the concept of coproduction factors in networks and the review of its relationship with relational consequents of attitudinal nature;

(ii) dimensioning of the influence of the coproduction factors of primary and secondary agents on satisfaction and pride of service users; (iii) dimensioning of the network effect on satisfaction and pride of service users; and, (iv) to note the implications of these relations for the strategy of primary and secondary network agents for the provision of shared services.

The structure of the article begins by presenting the theoretical and empirical framework, in which we reviewed the notions of strategic networks and network effect. In this framework we also detailed the concept of co-production factors in networks, and we discuss its association with relational consequents of attitudinal nature, and developed the hypothesis of this study. Following that, the methodological procedures are described, and the data analysis and discussion of results are presented. The paper ends with a section dedicated to the conclusions and limitations of the study.

\section{STRATEGIC NETWORKS AND COPRODUCTION FACTORS}

Strategic networks are arrangements or intentional ways of organizing productive activity through the cooperation of two or more agents, in order to achieve a superior 
performance (JARILLO, 1988; CAPALDO, 2007; SOH, 2010). Soh (2010) states that these arrangements allow faster product improvements and more agile response to the market, so these partnerships are intentionally structured. Capaldo (2007, p 586) states that strategic networks are assets that allow companies to be more "leveraged in order to generate returns to the participating organizations of the network and for the network as a whole".

The formation of these networks for the cooperation between several organizations frequently demands similarities in values, status, trust and objectives (AHUJA; POLIDORO; MITCHELL, 2009; BORYS; JEMISON, 1989; ZENG; CHEN, 2003; FAEMS; JANSSENS; MADHOK; LOOY, 2008), but on the other hand it also requires differences, in particular resources, so that there may be in fact the complementarity in carrying out activities that would not be performed in the same manner without the formation of alliances (LAVIE, 2006; SOH, 2011). In this regard, several studies have highlighted the association of these agents' resources in strategic networks with its consequent.

Hess and Rothaermel (2011), for example, verified that the combination and the adjustment between partners' resources in alliances are key aspects for innovation in the pharmaceutical industry. Mcevily and Marcus (2005) pointed out that the application of specific knowledge (idiosyncratic), though complementary, from each agent for joint operational troubleshooting on strategic alliances allow the acquisition of new competitive capabilities. Mahmood, Zhu and Zajac (2011) identified empirically that the heterogeneity of the resources present in the inter-organizational social networks in alliances favors nonredundant acquisition of research and capacity development (R\&D). Dyer and Hatch (2006) called specific capabilities to the relationship, those features that are idiosyncratic to network agents, and which result in a faster learning and superior performance. Mitsuhashi and Greve (2009), in turn, verified that the formation and the continuity of strategic alliances depend on market complementarity (differences in resources) and also the compatibility (similarity) of resources of the organizations that make up the network of shared services of maritime transport.

Taken together, these studies prioritize the differences in resources of agents participating in networks. In this sense, it is proposed in this paper to demarcate more clearly such differences, between primary and secondary agents, for examination of the influence of these assets on the relational consequents, especially attitudinal nature. Thus, these idiosyncratic resources are defined as network production factors. More specifically, coproduction factors of the primary and secondary network agents are resources considered 
non-redundant and centrally employed in shared service provisioning and that are perceived by the manager as important to the point of influencing singly or in interaction (network effect) the attitude in relation to network organizations. This logic is represented graphically in Figure 1, but highlights the network effect (moderation) only of the coproduction factors of the secondary agents on the factors of the primary agent (hub) and its association with attitudinal consequent to the latter. The latent factors used in the operationalization of the constructs co-production factors and relational consequent are highlighted in bold also in Figure 1.

Hub Classes Service Structure (Faculty)

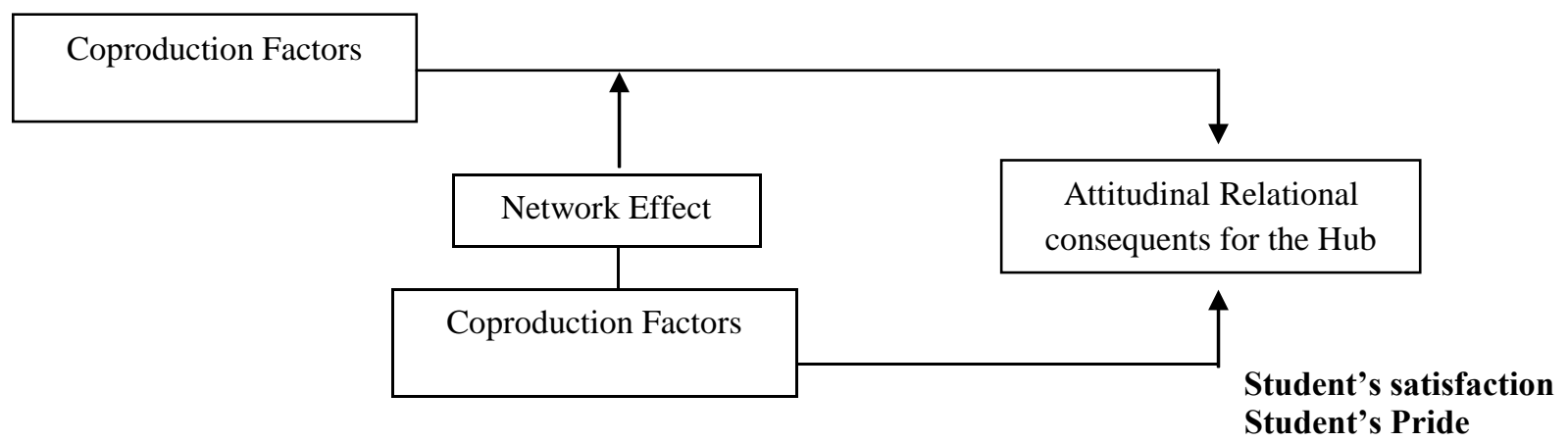

Service structure of the secondary agent

Figure 1 - Model of coproduction factors and attitudinal relational consequents for the hub.

\subsection{COPRODUCTION FACTORS AND ATTITUDINAL CONSEQUENTS}

Considering the above model in Figure 1, we pretend to analyze in the present study how the factors of coproduction in networks, therefore the primary agent (hub) and the secondary agents singly and in interaction (network effect), relate with the satisfaction and pride of the service user of distance learning with the actual primary agent. It is reiterated that the direction of the network effect (moderation) of an agent over another could be reversed, but as strategic networks are often defined by the primary agent, the influence that secondary agents present on the hub seems more important in terms of strategy (HOETKER; MELLEWIGT, 2009; INKPEN; TSANG, 2005). Regarding the examination of the relational consequent of attitudinal nature, as stated, the user satisfaction and pride constructs were selected. These constructs were chosen because they are necessarily attitudinal, but carry contrasting characteristics. While satisfaction is a result of the relationship between the service user's expectations and the performance of this service, pride emerges from the assessment that the user makes of themselves. In this sense, satisfaction has a locus of external attribution and pride has a locus of internal attribution (OLIVER, 2010). 
Regarding satisfaction, Anderson, Fornell and Lehmann (1994) point out that there are two perspectives more thoroughly employed in the definition of this construct: the one specific to the transaction and the cumulative one. The specific perspective to the transaction takes satisfaction as a result of a post-purchase trial, in a specific occasion in time and space, while the cumulative perspective conceives customer satisfaction as an ovall assessment regarding a good or a service, and it derives from the consumption experience over time.

Following the same reasoning, Oliver (2010) also reinforces the relational nature of the cumulative perspective when defining satisfaction as a global response of affective and cognitive nature, resulting from the experience with a good or service. Thus, this latter perspective conceives satisfaction within molds that are not only transactional, but relational, which, in turn, allows the index of this measure to be seen as more consistent in terms of past, current or future performance of the organization. The characterization of satisfaction as one of the dimensions of organizational performance is enhanced by its relationship to other objective measures (e.g., ROA). Hallowell (1996), for example, identified a positive and significant association between overall customer satisfaction and return on assets of retail banks. And Anderson, Fornell and Lehmann (1994) had also found the same relationship when they considered various sectors in Sweden.

Whilst it remains a relational consequent and one of the dimensions of organizational performance, the user's satisfaction with the service provided by the network depends so directly from the coproduction factors of primary and secondary agents. And for empirical verification of the influence of these factors it is argued that an ad hoc classification is always more appropriate, as is proposed in the present study. The literature specialized in the relationship of off-campus teaching-learning, based on central configuration (hub) and educational centers, highlights the practical importance of the faculty and the structure of service provision, which are provided by the central as well as the service structure provided by the hub frequented by the user (e.g., FALOON, 2011; LEMAK; SHIN; REED; MONTGOMERY, 2005; CHANG; SMITH, 2008; BEQIRI; CHASE; BISHKA, 2010; BRYANT; KAHLE; SCHAFER, 2005).

Thus, we defined for the operationalization of the concept coproduction factors in networks of DE (distance education) the following elements: (i) coproduction factor service structure of the primary agent; (ii) coproduction factor faculty (provided by the primary agent); and, (iii) coproduction factor service structure of secondary agents. Thus, the 
relationship between the performance of these factors and the user's satisfaction with the primary agent has supported the development of the following hypothesis:

Hypothesis 1 $1_{a}$ : The performance of the coproduction factor service structure of the primary agent (central) of the network is positively related to the user's satisfaction in relation to the primary agent.

Hypothesis 2 : The performance of the coproduction factor called teachers provided by the primary agent (central) of the network is positively related to the user's satisfaction in relation to the primary agent.

Hypothesis $3_{a}$ : The performance of the coproduction factor service structure of the secondary agent (hub) of the network is positively related to the user's satisfaction in relation to the primary agent.

In turn, the relational consequent pride, according to Oliver (2010), is a self-conscious emotion, related to satisfaction, but differentiated according to their internal locus of attribution. This means that the success of a given product use stems from the user's competence in making their choice, rather than from external factors such as would be the characteristics of the good or service. In this sense, pride means for the user personal competence, therefore an affective response to a cognition (interpretation of a situation). Lewis (1993) details this conception of pride and emphasizes that it is not a self-conscious emotion because it requires specific cognitive abilities to occur. Unlike some primary emotions (e.g., happiness, sadness) pride requires cognitive processes that necessarily involves the notion of self (knowledge about oneself) and also knowledge of objectives, rules and social standards regarded as important, to the point that it serves as a reference at the time of self-evaluation (self-centered) in relation to certain cognitive events. As Lewis points out (1993), the examination of pride requires analytically separating the object (behavior in a given event) and the self.

Thus, the acknowledgement, through self-assessment, of success or failure, or labeling oneself as competent or incompetent, results from the individual's behavior and from the sense of responsibility for their own behavior in a cognitive event. Cognitive events are operationalized here as interpreted situations resulting from the experience with the coproduction factors of the primary agent (DE central) and secondary (DE hubs) in the shared service provisioning. Thus, as in relation to satisfaction, it is expected that the three coproduction factors (service structure of the primary agent, faculty and service structure of 
secondary agents) show positive relations also with the user's pride toward the primary agent in providing distance education service. Considering the user's experience with the coproduction factors as cognitive events the following hypotheses were developed:

Hypothesis $\mathbf{1}_{b}$ : The performance of the coproduction factor service structure of the primary agent (central) of the network is positively related to the user's pride in relation to the primary agent.

Hypothesis $2_{b}$ : The performance of the coproduction factor called teachers provided by the primary agent (central) of the network is positively related to the user's pride in relation to the primary agent.

Hypothesis $3_{b}$ : The performance of the coproduction factor service structure of the secondary agent (hub) of the network is positively related to the user's pride in relation to the primary agent.

\subsection{NETWORK EFFECT AND ATTITUDINAL CONSEQUENTS}

The influence of the coproduction factors of the primary and secondary agents of strategic networks does not only occur singly, as shown in previous hypothesis, but also in interaction, which is called network effect. As shown in Figure 1, the proposed analysis model reflects the dynamic in which the performance of secondary agents (e.g., quality of the coproduction factors of the on-site teaching hubs) moderates the influence of the primary agent performance (e.g., coproduction factors of the center of distance education) on relational consequents of attitudinal nature (i.e., user's satisfaction and pride with the primary agent or hub). This definition of network effect, for attitudinal dependent variables, favors a relational view for the consideration of the partners' resources in networks type alliances.

According to a relational view of organizational resources (LAVIE, 2006; DYER; HATCH, 2006), alliances are created especially when the partners (primary and secondary agents) judge that certain benefits cannot be achieved through an independent action. Thus, from this imperative, these resources must satisfy the complementarity condition, which in turn requires that such organizational assets to be different among the network partners. And the effectiveness of the adjustment or complementarity between these resources can be evaluated by the network effect. If the resources, for example, of the secondary agent are complementary to the resources of the primary agent the latter agent should take advantage not only of the use of the partner's resources singly, but in interaction with their own resources. 
Having the constructs user's satisfaction and pride as consequents of the network agents' coproduction factors it is necessary then to specify how such factors act singly but also in interaction (moderation). Isolated effects of these factors were presented in the previous hypothesis. The effects of interaction, representing the network effect, result from the moderation of the coproduction factor service structure of the secondary agent in the relationship between primary agent service structure on satisfaction and on the user's pride with the hub. Similarly, the network effect also results from the moderating coproduction factor service structure of the secondary agent in the relationship between the faculty provided by the primary agent on the constructs satisfaction and pride. The examination of possible interactions and their effects gave subsidies for the development of the following hypothesis:

Hypothesis $4_{a}$ : The performance of the coproduction factor service structure of the secondary agent (hub) of the network moderates the relationship of the service structure of the primary agent (center) of the user's satisfaction with the primary agent.

Hypothesis $\mathbf{4}_{b}$ : The performance of the coproduction factor service structure of the secondary agent (hub) of the network moderates the relationship of the service structure of the primary agent (center) of the user's pride with the primary agent.

Hypothesis $4_{c}$ : The performance of the coproduction factor service structure of the secondary agent (hub) of the network moderates the relationship of the faculty provided by the primary agent (center) with the user's satisfaction with the primary agent.

Hypothesis $4_{d}$ : The performance of the coproduction factor service structure of the secondary agent (hub) of the network moderates the relationship of the faculty provided by the primary agent (center) of the network with the user's pride with the primary agent.

\section{METHODOLOGICAL PROCEDURES}

The methodological procedures that have guided the development of the study are detailed in this section. The selected method was the survey, which consists of collecting data through a structured questionnaire. The study population was approximately eighty thousand students enrolled in nine higher education courses offered by an institution with a central unit (hub or primary agent) in Curitiba-PR, in partnership with more than four hundred poles (secondary agents) of distance education. These centers are established in all capitals and other municipalities of the five regions of Brazil. For data collection we developed a virtual questionnaire and sent it by e-mail to all students as a way of inviting to participate in a survey to evaluate distance education service. The sample was non-probabilistic and by 
adhesion. Seven thousand one hundred thirty-eight observations were considered valid after evaluating the number of missing values and lack of minimal variation in responses.

\subsection{MEASURES}

Indexes for assessing user's satisfaction with the institution of higher learning in the distance education mode were extracted from Fornell (1992). The three items of the scale were adapted to measure respectively: (i) overall satisfaction with the institution; (ii) confirming expectations; and (iii) distance from an ideal hypothetical institution. To evaluate pride two indexes for the Likert scale were developed. In the first item of the scale the service user (student) answered as to how proud they felt and the second index as to what extent the choice of the institution was a reason to be proud of.

Coproduction factors of primary and secondary agents were initially defined from the literature (e.g., FALOON, 2011; LEMAK; SHIN; REED; MONTGOMERY, 2005; CHANG; SMITH, 2008; BEQIRI; CHASE; BISHKA, 2010; BRYANT; KAHLE; SCHAFER, 2005)

and refined with the completion of nineteen interviews with students and two interviews with course coordinators in the institution, who confirmed the items that would have the greatest impact on satisfaction and pride of the student. This stage of development of the indexes pointed to the existence of one dimension (service structure pole) for the coproduction factor of secondary agents and two dimensions (structure and faculty) for coproduction factors of the primary agent (DE center in Curitiba). The items evaluated in the coproduction factors were: perceived quality of the pole's service structure (the pole's physical structure, on-site tutoring, pole's library); perceived quality of the DE's central service structure in Curitiba (teaching materials sent by mail, telephone tutoring, secretarial office, virtual academic system); and, the perceived quality of the faculty provided by the central or the hub of the network (explanation, knowledge, clarity). The scale for assessing the performance of production factors ranged from: (1) far below expectations up to (10) far above expectations. Following the recommendation by Fornell (1992), all indexes of the questionnaire were evaluated with ten points on the scale. This procedure aims at maximizing the variance of responses and lower asymmetry. Age, course and region were information collected for control variables in the regression.

\subsection{DATA PROCESSING}

The first step of the analysis consisted in the evaluation of data quality (for example, normality and outliers). Following, we applied the application of the Confirmatory Factor Analysis to validate the scales and the Multiple Regression Analysis to test the hypotheses. 


\section{DATA ANALYSIS}

The average age of respondents was 35 years. The sample was divided into $60.20 \%$ of male students and $39.80 \%$ female. The representation of respondents in the final sample per region in Brazil was as follows in absolute numbers: North $(n=492)$; Northeast $(n=515)$; Midwest ( $n=354)$; Southeast $(n=2472)$; South $(n=3305)$.

After the description of the main characteristics of the sample interval the data were subjected to an examination of outliers, extreme values and normality. The exclusion of extreme values and outliers do not indicate substantial differences regarding the results of the regression analysis to the whole sample. Thus, we decided to keep all observations in further analysis. The Kolmogorov-Smirnov test showed that none of the interval variables presented normal distribution. However, asymmetry values ranging between -0.550 and -1.421 , therefore, all under \pm 1.50 , thus allowing a relaxation of the assumption of normality and the application of the Structural Equation Modeling for the Confirmatory Factor Analysis (CFA). According to Schumacker and Lomax (2004) values of asymmetry in this amplitude allow the use of maximum likelihood estimate without losses (e.g., error Type I and Type II). The data quality survey results allow the application of the CFA to evaluate the convergent and discriminant validity of the measures.

\subsection{VALIDITY AND RELIABILITY OF THE MEASURES}

The Confirmatory Factor Analysis (CFA) was applied in a set of fifteen manifest variables distributed in five latent variables. From the method of maximum likelihood the application of the technique showed a good adjustment from the data matrix to the theoretical matrix. Adjustment measures were divided into: (i) general adjustments measures (GFI = 0.924 and RMSEA=0.08); (ii) incremental adjustment measures (TLI=0.944 and NFI=0.957), and; (iii) parsimonious adjustment measures $(\mathrm{CFI}=0.958$; $\mathrm{IFI}=0.958)$. The RMSEA must be equal or lower than 0.08 while other measures should be above 0.900 . Other measures such as

$2 /$ degrees of freedom, sensitive to the high number of observations were not considered in the adjustment assessment. Table 1 shows the loadings of the manifested variables, compound reliability, the average variance extracted and the Cronbach's alpha. 
Table 1 - Results of the Confirmatory Factor Analysis

\begin{tabular}{|c|c|}
\hline Index & Loadings \\
\hline \multicolumn{2}{|l|}{ Central (Structure) $(\mathrm{AVE}=0.58 ;$ Compound Reliability=0.80; $a=0.79)$} \\
\hline Quality of teaching materials sent by mail. & 0.755 \\
\hline Capacity of the central tutors to clarify questions by telephone. & 0.760 \\
\hline Service of the central office. & 0.722 \\
\hline Speed in updating information in the virtual academic system. & 0.790 \\
\hline \multicolumn{2}{|l|}{ Central (Faculty) $(\mathrm{AVE}=0.84 ;$ Compound Reliability $=0.93 ; a=0.94)$} \\
\hline Teachers' explanation on the subjects during lessons. & 0.828 \\
\hline How much teachers understand about the subjects that they teach. & 0.956 \\
\hline Clarity in teachers' explanations during class. & 0.956 \\
\hline \multicolumn{2}{|l|}{ Pole (structure) $(\mathrm{AVE}=0.73 ;$ Compound Reliability $=0.88 ; a=0.87)$} \\
\hline Physical structure of the classroom. & 0.635 \\
\hline Support and quality of on-site classroom teaching. & 0.942 \\
\hline Books available in the library for the classroom. & 0.949 \\
\hline \multicolumn{2}{|l|}{ Satisfaction (AVE=0.82; Compound Reliability $=0.93 ; a=0.93$ ) } \\
\hline Indicate how satisfied you are in general with your college. & 0.883 \\
\hline Indicate how satisfied you are with the teaching considering your expectations. & 0.905 \\
\hline Indicate how far/close your college is to what is considered the ideal college. & 0.923 \\
\hline \multicolumn{2}{|l|}{ Pride $(\mathrm{AVE}=0.92 ;$ Compound Reliability $=0.95 ; a=0.96)$} \\
\hline I'm proud to study in this college (university). & 0.961 \\
\hline Have chosen to be part of this institution is a source of pride for me. & 0.959 \\
\hline
\end{tabular}

Source: Developed by authors.

References: $\boldsymbol{a}$-Cronbach's Alpha (0.60); Compound reliability (0.70); AVE- Average Variance Extracted $(0,50)$.

The reliability of the measurements was assured from the observation of the Variance Average Extracted (AVE), the Compound Reliability and the Cronbach's Alpha. All indexes were above the references. The convergent validity of the measures were confirmed by statistical significance $(p$-value $<0.05)$ the standardized load of the indicators. And the discriminant validity was evidenced when comparing the correlation of factors (squared) with the Average Variance Extracted (AVE) of each latent variable, wherein the squared correlation was not greater than the AVE in any case. 


\subsection{REGRESSION ANALYSIS FOR TEST OF HYPOTHESES}

After the evaluation of the measures the latent variables were correlated and also analyzed in terms of mean and standard deviation, as shown in Table 2 . The positive and significant association between the variables appeared to be suitable for a later Multiple regression Analysis to test the hypotheses. The results of the Ordinary Least Square regression are presented in Table 3.

Table 2 - Mean, Standard Deviation and Correlations Between Latent Variables

\begin{tabular}{|c|c|c|c|c|c|c|c|}
\hline & $\bar{x}$ & $S$ & (1) & (2) & (3) & (4) & $(5)$ \\
\hline (1) Central (Structure) & 7,55 & 1,55 & 1 & & & & \\
\hline (2) Central (Faculty) & 8.09 & 1.52 & $0.654 * * *$ & 1 & & & \\
\hline (3) Pole (Structure) & 7.72 & 1.69 & $0.737 * * *$ & $0.510 * * *$ & 1 & & \\
\hline (4) Satisfaction & 7.71 & 1.55 & $0.756 * * *$ & $0.672 * * *$ & $0.625 * * *$ & 1 & \\
\hline (5) Pride & 7.50 & 1.66 & $0.687 * * *$ & $0.557 * * *$ & $0.596 * * *$ & $0.722 * * *$ & 1 \\
\hline
\end{tabular}

$* * * p$-value $<0.01$

Source: Developed by authors.

Table 3 - Regression Analysis Results OLS

\begin{tabular}{|c|c|c|}
\hline & Model 1 & Model 2 \\
\hline & Satisfaction & Pride \\
\hline \multicolumn{3}{|l|}{ Control Variables } \\
\hline Log Age & $0.026(3.186) * * *$ & $0.033(3.494) * * *$ \\
\hline Dummy Gender & $0.047(5.561)^{* * *}$ & $0.024(2.518)^{* *}$ \\
\hline Dummy Course 1 & $-0.019(-2.135)^{* *}$ & $-0.021(-2.036) * *$ \\
\hline Dummy Course 2 & $-0.019(-2.325) * *$ & $0.001(0.063)$ \\
\hline Dummy Course 3 & $-0.006(-0.588)$ & $0.016(1.453)$ \\
\hline Dummy Course 4 & $-0.015(-1.736)$ & $-0.022(-2.204)^{* *}$ \\
\hline Dummy Course 5 & $-0.025(-2.733) * * *$ & $-0.001(-0.074)$ \\
\hline Dummy Course 6 & $-0.041(-4.534) * * *$ & $-0.037(-3.570)^{* * *}$ \\
\hline Dummy Course 7 & $-0.030(-3.006) * * *$ & $-0.011(-0.914)$ \\
\hline Dummy Course 8 & $-0.004(-0.464)$ & $0.006(0.581)$ \\
\hline Dummy North Region & $0.014(1.373)$ & $0.028(2.346)^{* *}$ \\
\hline Dummy Midwest Region & $0.016(1.598)$ & $0.003(0.278)$ \\
\hline Dummy Southeast Region & $0.032(2.039)^{* *}$ & $-0.009(-0.495)$ \\
\hline Dummy South Region & $0.022(1.385)$ & $0.009(0.498)$ \\
\hline \multicolumn{3}{|l|}{ Main Effect Variables } \\
\hline Central (Structure) $€$ & $0.451(35.105)^{* * *}$ & $0,422(28.620)^{* * *}$ \\
\hline Central (Faculty) $\mathbf{z}$ & $0.305(28.701)^{* * *}$ & $0,186(15.288)^{* * *}$ \\
\hline Pole (Structure) $€$ & $0.132(11.171)^{* * *}$ & $0,215(15.899)^{* * *}$ \\
\hline \multicolumn{3}{|l|}{ Interaction Variables } \\
\hline Pole x Central (Structural) & $0.022(1.727)^{*}$ & $0.082(5.663) * * *$ \\
\hline Pole x Central (Faculty) & $-0.013(-1.020)$ & $-0.010(-0.710)$ \\
\hline \multicolumn{3}{|l|}{ Model Adjustments } \\
\hline $\mathrm{F}$ & $556.501 * * *$ & $342.320 * * *$ \\
\hline $\mathrm{R}^{2}$ & 0.628 & 0.510 \\
\hline $\mathrm{R}^{2}$ Adjusted & 0.627 & 0.508 \\
\hline
\end{tabular}


Four regression models were generated. In the first one, only the control variables were used as independent variables of satisfaction. The same control variables were kept in the second model, but the dependent variable was the user's pride with the DE center. Both models were statistically significant, but showed low explanatory power, with the $\mathrm{R}^{2}$ adjusted of 0.026 and 0.018 respectively. We chose not to present in detail these test models of the control variables.

Following that, control variables were kept and the variables of main effect and interaction were also included in the following two models shown in Table 3. Model 1 of Table 3 has the user's satisfaction with the center as the dependent variable and model 2 the variable pride in relation to the center as the dependent variable. The first model was significant at a p-value $<0.01(\mathrm{~F}=556,501)$ with adjusted $\mathrm{R} 2=0.627$. Thus, the two models "explain", respectively, $62 \%$ and $50 \%$ of the variation in the user's satisfaction and pride in relation to the higher education institution which operates as a DE center. Both models allowed the verification of the hypotheses of the study.

In model 1 , the hypothesis $\left(1_{a}\right)$, which relates the primary coproduction factor service structure of the primary agent with the user's satisfaction with this same agent presented a $\beta=0.451$ ( $p$-value $<0.01$ ). Hypothesis $\left(2_{a}\right)$ supports a positive relationship between the socalled coproduction factor "faculty provided by the primary agent" (central) with the user's satisfaction. This hypothesis was also confirmed $(\beta=0.305, p$-value $<0.01)$. The hypothesis $\left(3_{a}\right)$, which associates the coproduction factor service structure of the secondary agent (pole) of the network with the user's satisfaction presented a $\beta=0.132$ ( $p$-value $<0.01$ ). Therefore, by singly observing each one of the coproduction factors in networks and its effects on satisfaction it is possible to state that there is an association between these elements and also a hierarchy of the effects of such factors, being the structure and the faculty provided by the center the most influential elements.

In model 2 , the hypothesis $\left(1_{b}\right)$, in which we state that the performance of the coproduction factor service structure of the primary agent (central) of the network is positively related to the user's pride in relation to the primary agent, a $\beta=0.422$ ( $p$-value $<0.01)$ was corroborated. The hypothesis $(2 b)$ confirmed the expected influence of the socalled performance coproduction factor "faculty provided by the primary agent" (central) with the user's pride regarding this agent $\left(\beta=0.186\right.$, p-value <0.01). Hypothesis $\left(3_{b}\right)$ also corroborated with the influence of the performance of the coproduction factor service structure of the secondary agent (pole) on the user's pride in relation to the primary agent 
( $\beta=0.215$, p-value <0.01). This second model showed that in the relationship of the coproduction factors with the user's pride, the effect of the central's structure is the also the most important element, but the factor "faculty provided by the primary agents" has a lesser effect when compared to the coproduction factor service structure pole.

In relation to the network effect, tested through the interaction variables, only two of the four hypotheses were confirmed. The moderation of the coproduction factor of the pole on the relation between the coproduction factor service structure of the center and the satisfaction (hypothesis $4 a$ ) appears with a $\beta=0.022$. This relationship is significant, but only when a $p$ value $<0.10$. In the case of the same moderation of these variables with pride (hypothesis $4 b$ ) the relationship is stronger $(\beta=0.082, p$-value $<0.01)$. The hypotheses which predicted the moderation of the coproduction factor performance service structure of the secondary agent (pole) of the network on the relationship of the faculty provided by the primary agent (central) with the user's satisfaction (hypothesis $4_{c}$ ) and with the user's pride (hypothesis $4_{d}$ ) were not confirmed.

\section{RESULTS DISCUSSION}

The analysis' results, which corroborate with eight of the ten hypotheses, confirm the existence of differentiated effects, and above all significant of the coproduction factors of the primary and secondary agents in networks on relational consequents of attitudinal nature. Regarding the dimensioning of such effects, considered from the values of the coefficients of the Multiple Regression Analysis, we highlight the greatest influence of the coproduction factors on the user's satisfaction (student) resides on the primary agent (DE center) when compared to the secondary agent (DE poles).

According to the confirmation of the hypotheses both the service structure and the faculty provided by the DE center presented greater influence on satisfaction than the influence of the pole's service structure. Such acknowledgements reveal the greater responsibility of the primary agent in networks with shared services provisioning, but also a less dependency (relative) performance of coproduction factors of secondary agents when it comes to user's satisfaction.

The variation in the user's pride in relation to the higher education institution (primary agent) also occurs due to the coproduction factors of primary and secondary agents. As the hypotheses confirmations were attested, the service structure and the faculty provided by the DE center, and also the poles' service structure, positively and significantly relate with pride. 
However, in the case of this particular variable, one must consider that the pole has a stronger influence than at least one of the coproduction factors of the primary agent (i.e., faculty).

Therefore, all the first six developed hypotheses in the referential were corroborated, which shows, as proposed, the existence of relationships between the resources of the different agents in the network and consequents of a nature that is not strictly economic (AREND, 2009; ZHANG; LI, 2010; LIN; YANG; ARYA, 2009). Although researchers such as Hess and Rothaermel (2011) attributing the same importance to the resources of different agents in innovation activities and Mcevily and Marcus (2005) identifying that the different organizations knowledge resources on networks contribute in the acquisition of new skills, the attitudinal consequents of the complementary resources in networks have not yet been placed in evidence in a manner sufficiently clear. In this sense, the above results indicate new possibilities for research.

Besides the isolated influence of coproduction factors in networks on attitudinal consequents we also examined the network effect on the constructs pride and the user's satisfaction with the primary agent (DE center). As presented, the network effect was evaluated from the interaction between the coproduction factor of the poles (service structure) with the coproduction factors of the DE center. The hypotheses tested with the interaction variables, for satisfaction and pride as dependent variables confirmed the moderating effect of the pole (service structure) in the relationship of the main hub (service structure) and the attitudinal constructs (satisfaction and pride of the user).

The same moderation for the relation between the pole and the faculty was not confirmed for satisfaction or pride. Thus, it is worth mentioning that the network effect, tested through these hypotheses, occurred among resources of the same nature, that is, the service structure of an agent on the service structure of the other agent. It is also important to highlight that moderation occurs more intensely in the case of the pride variable and less sharply to the dependent variable satisfaction. This difference in the intensity of these moderations also occurs because of the nature of these two attitudinal variables. While satisfaction has a locus of external attribution (OLIVER, 2010) pride has a locus of internal attribution (LEWIS, 1993). Therefore, we verified that the performance evaluation of the interacting coproduction factors have a greater effect on self-conscious emotion and a lesser effect on a response of nature affective, but that is still predominantly cognitive, and occurs most directly from a consumption experience (i.e., satisfaction). 
Overall, the results allow a hierarchization of the influence of coproduction factors in strategic networks of shared service provisioning of distance education. As shown, when examining the variation in satisfaction the central service structure proves to be more important. Thus, such things as teaching materials sent by mail, telephone tutoring, secretarial office and virtual academic system of the central hub are among the key elements to achieving greater user satisfaction indexes with the primary agent (DE center), next to items such as the pole's physical structure, on-site classroom tutoring and the pole's library.

That same reasoning of hierarchization of the coproduction factor, faculty, when evaluated from the explanation criterion, knowledge and clarity, operates as an element of lesser importance to the elements of the central service structure. However, when the dependent variable is pride in relation to the institution operating as the hub, even if the central service structure continues to be more important than other elements the pole's service structure surpasses the importance of the faculty. Therefore, even if satisfaction depends on the structure and on the hub's faculty e more peripherally on the pole, pride depends mainly on service criterion of support for the teaching of both the central (main hub) as well as for the poles.

Regarding the network effect, we confirmed the concept of coproduction factors by effectively highlighting the complementarity of the coproduction factors of the different agents when attitudinal variables are considered deriving from service provisioning through alliance type cooperation. The implications of these findings are not restricted to the network element but also are based on the notion of co-strategy, which reveals the existence of a common line of action characterized by heavy reliance on the execution of activities. Even though primary and secondary agents in alliance type networks have their own competitive strategies, they present elements of connection with the activities that constitute the strategy of their co-agents. When the activities of an agent are performed at levels that are considered positive the activities of the other agent suffer these effects as well.

\section{CONCLUSIONS}

The present study had as its objective to verify the relation between the performance of coproduction factors of a primary agent (hub or distance education center), of the various secondary agents (440 learning centers scattered throughout Brazil) and of the network effect (interaction between these agents' factors performance) on satisfaction and pride of users (students), with a distance learning higher institution (hub) in Brazil. 
Perhaps the main limitation is the inability to relate the performance of co-production factors of primary and secondary agents with economic performance as well. In situations in which there is this additional check it will be possible to strengthen the validity of the empirical findings of this research.

The main contribution of the paper focuses on the proposal of the concept of coproduction factors of primary and secondary agents of the type alliance networks, and on the examination of the relationship with its attitudinal consequent. Coproduction factors were defined here as resources considered non-redundant and put into use centrally in the shared service provisioning and which are also perceived by the users and managers as being important to point of influencing, singly or in by interaction (network effect), the attitude towards network organizations. As pointed out, the network effect could have been examined from the influence of the primary agent (hub) on the secondary agent, however, the most common direction in consideration of this effect is the opposite direction, as shown in Figure 1.

Regarding the results, it is worth mentioning that there effectively exists an influence of the coproduction factors, as proposed in the present study, on relational consequents of attitudinal nature. Although most of the studies in this line assess such effects on economic variables there are possibilities of expanding the theorizing about the notion of resources in networks and especially on the network effect.

Finally, the studies provides a hierarchy of coproduction factors in strategic networks for shared services provisioning of distance education when considering their effects on the user's satisfaction and pride in the institution of higher education. The central service structure appears as the first element in importance for the increase in satisfaction, when considering the beta and its statistical significance. Therefore, educational materials, telephone tutoring, secretarial office and the virtual academic system of the main hub are characteristics that the primary agent (DE center) must consider first. In the second place is the influence of the teaching quality. In third place, the pole's structure, from the items: pole's physical structure, on-site teaching and the pole's library. The hierarchization of the most important factors in the case of pride also begins with the central service structure. The second factor in importance is the pole's structure and thirdly the faculty. The interaction between the factors of primary and secondary agents appears fourth in the hierarchy of influence on satisfaction and pride, but only for the structure variables. 
These findings can point out some practical implications. The first one is that care must be taken in the selection of network partners appearing as secondary shared service provisioning agents. The discussed results show that the quality of the secondary agent's structure relates to the quality of the structure of the primary agent. In this sense, choosing a partner with less qualified. In this sense, choosing a partner with less qualified resources can impede the realization of relational incomes, that is, advantages resulting from the connection between the organizations making up the network. The second implication resides in the importance of the control of appropriations or qualification of the partner's resources in the network. In addition to selecting partners with comparable or superior qualities to the hub in their resources it is necessary to monitor the maintenance of this quality.

In general, we conclude that the concept of coproduction factors allows us not only the hierarchization of the factors, but also the dimensioning of the influence of the primary agent (DE center) and of the secondary agents (poles) on relational consequents of the network, which in turn contributes to the discussion on degrees of dependence and interdependence of the strategies and co-strategies of these agents.

\section{REFERENCES}

AHUJA, G.; POLIDORO, F.; MITCHELL, W. Structural homophily or social asymmetry? The formation of alliances by poorly embedded firms. Strategic Management Journal, v.30, n.9, p. 941-958, 2009.

ANDERSON, E. W.; FORNELL, C.; LEHMANN, D. R. Customer satisfaction, market share, and profitability: findings from Sweden. Journal of Marketing, v.58, n.3, p. 53-66, 1994.

AREND, R. J. Reputation for cooperation: contingent benefits in alliance activity. Strategic Management Journal, v.30, n.4, p. 371-385, 2009.

BEQIRI, M. S.; CHASE, N. M.; BISHKA, A. Online course delivery: an empirical investigation of factors affecting student satisfaction. Journal of Education for Business, v.85, n.1, p. 95-100, 2010.

BORYS, B.; JEMISON, D. B. Hybrid arrangements as strategic alliances: theoretical issues in organizational combinations. Academy of Management Review, v.14, n.2, p. 234-249, 1989.

BRYANT, S. M.; KAHLE, J. B.; SCHAFER, B. A. Distance education: a review of the contemporary literature. Issues in Accounting Education, v.20, n.3, p. 255-272, 2005.

CAPALDO, A. Network structure and innovation: the leveraging of a dual network as a distinctive relational capability. Strategic Management Journal, v.28, n.6, p. 585-608, 2007. 
CHANG, S. H. H.; SMITH, R. A. Effectiveness of personal interaction in a learner-centered paradigm distance education class based on student satisfaction. Journal of Research on Technology in Education, v.40, n.4, p. 407-426, 2008.

DYER, J. H.; HATCH, N. W. Relation-specific capabilities and barriers to knowledge transfers: creating advantage through network relationships. Strategic Management Journal, v.27, n.8, p. 701-719, 2006.

FAEMS, D. et al. Toward an integrative perspective on alliance governance: connecting contract design, trust dynamics, and contract application. Academy of Management Journal, v.51, n.6. p. 1053-1078, 2008.

FALOON, G. Making the connection: Moore`s theory of transactional distance and its relevance to the use of a virtual classroom in postgraduate online teacher education. Journal of Research on Technology in Education, v.43, n.3, p. 187-209, 2011.

FORNELL, C. A national customer satisfaction barometer: the Swedish experience. Journal of Marketing, v.56, n.1, p. 6-21, 1992.

GOERZEN, A. Alliance network and firm performance: the impact of repeated partnerships. Strategic Management Journal, v.28, n.5, p. 487-509, 2007.

GULATI, R.; LAVIE, D.; SINGH, H. The nature of partnering experience and the gains from alliances. Strategic Management Journal, v.30, n.11, p. 1213-1233, 2009.

GULATI, R. Alliances and networks. Strategic Management Journal, v.19, n.4, p. 293-317, 1998.

Network location and learning: the influence of network resources and firm capabilities on alliance formation. Strategic Management Journal, v.20, n.5, p. 397-420, 1999.

HAIR JUNIOR, J. F. et al. Multivariate data analysis. New Jersey: Prentice Hall, 2009.

HALLOWELL, R. The relationship of customer satisfaction, customer loyalty, and profitability: an empirical study. International Journal of Service Industry Management, v.7, n.4, p. 27-42, 1996.

HESS, A. M.; ROTHAERMEL, F. T. When are assets complementary? Star scientists, strategic alliances, and innovation in the pharmaceutical industry. Strategic Management Journal, v.32, n.8, p. 895-909, 2011.

HOETKER, G.; MELLEWIGT, T. Choice and performance of governance mechanisms: matching alliance governance to asset type. Strategic Management Journal, v.30, n.10, p. 1025-1044, 2009.

INKPEN, A. C.; TSANG, E. W. K. Social capital, networks, and knowledge transfer. Academy of Management Review, v.30, n.1, p. 146-165, 2005. 
JARILLO, J. C. On strategic networks. Strategic Management Journal, v.9, n.1, p. 31-41, 1988.

KANG, M. P.; MAHONEY, J. T.; TAN, D. Why firms make unilateral investments specific to other firms: the case of OEM suppliers. Strategic Management Journal, v.30, n.2, p. 117$135,2009$.

KOKA, B. R.; MADHAVAN, R.; PRESCOTT, J. E. The evolution of interfirm networks: environmental effects on patterns of network change. Academy of Management Review, v.31, n.3, p. 721-737, 2006.

KOKA, B. R.; PRESCOTT, J. E. Designing alliance networks: the influence of network position, environmental change, and strategy on firm performance. Strategic Management Journal, v.29, n.6, p. 639-661, 2008.

LAVIE, D. The competitive advantage of interconnected firms: an extension of the resourcebased view. Academy of Management Review, v.31, n.3, p. 638-658, 2006.

LEMAK, D. J. et al. Technology, transactional distance, and instructor effectiveness: an empirical investigation. Academy of Management Learning \& Education, v.4, n.2, p. 150$159,2005$.

LEWIS, M. Self-conscious emotions: embarrassment, pride, shame, and guilt. In: LEWIS, M.; HAVILAND, J. M. (Eds.). Handbook of emotions. New York: Guilford Press, 1993, p. 563-573.

LIN, Z.; YANG, H.; ARYA, B. Alliance partners and firm performance: resource complementarity and status association. Academy of Management Journal, v.30, n.9, p. 921-940, 2009.

LU, J. W.; MA, X. The contingent value of local partners` business group affiliations. Academy of Management Journal, v.51, n.2, p. 295-314, 2008.

LUNNAN, R. Predicting and measuring alliance performance: a multidimensional analysis. Strategic Management Journal, v.29, n.5, p. 545-556, 2008.

LUO, Y. Structuring interorganizational cooperation: the role of economic integration in strategic alliances. Strategic Management Journal, v.29, n.6, p. 617-637, 2008.

MAHMOOD, I. P.; ZHU, H.; ZAJAC, E. J. Where can capabilities come from? Network ties and capability acquisition in business groups. Strategic Management Journal, v.32, n.8, p. 820-848, 2011.

MCEVILY, B.;MARCUS, A. Embedded ties and the acquisition of competitive capabilities. Strategic Management Journal, v.26, n.11, p. 1033-1055, 2005.

MITSUHASHI, H.; GREVE, H. R. A matching theory of alliance formation and organizational success: complementarity and compatibility. Academy of Management Journal, v.52, n.5, p. 975-995, 2009. 
OLIVER, R. L. Satisfaction: a behavioral perspective on the consumer. New York: M. E. Sharpe, 2010.

OZCAN, P.; EISENHARDT, K. M. Origin of alliance portfolios: entrepreneurs, network strategies, and firm performance. Academy of Management Journal, v.52, n.2, p. 246-279, 2009.

SAMPSON, R. C. R\&D alliances and firm performance: the impact of technological diversity and alliance organization on innovation. Academy of Management Journal, v.50, n.2, p. 364-386, 2007.

SCHUMACKER, R. E.; LOMAX, R. G. A beginner's guide to structural equation modeling. Mah-wah: Lawrence Erlbaum Associates Publishers, 2004.

SHANER, J.; MAZNEVSKI, M. The relationships between networks, institutional development, and performance in foreign investments. Strategic Management Journal, v.32, n.5, p. 556-568, 2011.

$\mathrm{SOH}, \mathrm{P} . \mathrm{H}$. Network patterns and competitive advantage before the emergence of a dominant design. Strategic Management Journal, v.31, n.4, p. 438-461, 2011.

YU, J.; GILBERT, B. A. OVIATT, B. M. Effects of alliances, time, and network cohesion on the initiation of foreign sales by new ventures. Strategic Management Journal, v.32, n.4, p. 424-446, 2011.

ZENG, M.; CHEN, X. P. Achieving cooperation in multiparty alliances: a social dilemma approach to partnership management. Academy of Management Review, v.28, n.4, p. 587605, 2003.

ZHANG, Y.; LI, H. Innovation search of new ventures in a technology cluster: the role of ties with service intermediaries. Strategic Management Journal, v.31, n.1, p. 88-109, 2010. 